\title{
Management of Garbhasaya Greevagata Vrana (Cervical Ectopy) with Tankana Jala Yoni Dhavana and Aswattha Churna Orally (Under VIA And VILI)
}

\author{
ResearchArticle
}

\author{
Vishala Srinivas $\mathbf{T}^{1^{*}}$, Amruta Shirke ${ }^{2}$ \\ 1. Professor, Department of Prasuti Tantra, 2. PG scholar, \\ Yashwanth Ayurvedic College, Kodoli, Kolhapur, Maharashtra
}

\begin{abstract}
Cervical cancer continues to be a major health concern in the women from age 25 years to 60 years. Visual inspection with acetic acid and lugol's iodine is very simple to perform and cost effective, can be performed under low resource settings also. Garbhasaya greevagata vrana which can be understood as cervical ectopy according to modern science is one of the commonest encountered problem in gynecology practice. Screening programmes for the early detection of premalignant lesions of the cervix are expensive and technically difficult, especially in resource-challenged settings. There is a need for cheaper and equally effective alternative screening methods. METHODOLGY: A total of 112 parous females were registered with above symptoms. Ectopy cases were treated with distilled water prepared withTankan(borax), an alkaline preparation for 14 days daily once and subjected for repeat inspection after two months and 6 months. The interval between last day of therapy and re-inspection was one and half month. RESULTS: 100 patients completed the treatment.10 patients were found with ectopy, 7 patients were referred to higher centre with VIA and VILI positive, out of which 4 patients were confirmed with CIN1, 1 patient with Invasive carcinoma and rest were non- significant. 5 patients dropped out. All patients except positive cases were treated with Ayurvedic medication and all ectopy cases responded well. CONCLUSION: Before treating benign cervical lesions screening with VIA and VILI will be helpful in the early detection of cancer cervix. Ayurvedic treatment collaborated with more modern diagnostic methods help in more accurate approach in the management.
\end{abstract}

Keywords: VIA, VILI, CIN, Acetowhite, Squamo-columnar junction, Garbhasaya greevagata Vrana.

\section{Introduction:}

In the childbearing age more than $70 \%$ female population experience the symptoms of vulvo-vaginal itching, white discharge vaginally, dyspareunia and menstrual irregularities. Particularly in rural population women never turn up to a Gynecologist to get relief from the problem. Women resist undergoing vaginal examination in rural areas, giving way to miss the diagnosis of any abnormal changes on the cervix. Commonly the drug options for treating such conditions are orally and locally with metranidazole, clindazole and anti fungal drugs. Infections like Trichomonas vaginalis, candidiasis can be treated with these drugs but cervical ectopy will be persisting which need destruction of abnormal epithelium either by thermal cauterization or cryo cautery, which are having their own disadvantages like persistent vaginal discharge for more than 20 days which is very irritating for the patient. Ayurvedic principle of Kshara chikitsa, which consists of application of alkaline substance to perform the cauterization and can be considered as

\footnotetext{
*Corresponding Author:

Vishala Srinivas T

Professor, Department of Prasuti Tantra

Yashwanth Ayurvedic College, Kodoli

Kolhapur, Maharashtra

Email Id: vishalaturlapati@gmail.com
}

chemical cauterization, proved effective in treating such condition without any side effects. The major issue lies in treating cervical lesions like ectopy without ruling out the possibility of pre-malignant lesions, as the signs and symptoms does not vary much in both the conditions. Early detection of premalignant lesions helps to prevent cervical cancer $(1,2)$.

Cancer of the uterine cervix is a leading cause of mortality and morbidity among women worldwide. In developing countries it is the most common gynecological cancer and one of the leading causes of cancer deaths amongst women. Nearly 400,000 new cases of cervical cancer are diagnosed annually worldwide and $80 \%$ of these are diagnosed in the developing countries.(3) There are 1.7 million prevalent cases in the developing world and as many as 5-13 million women have precancerous lesions (4). As the female population in the developing countries continues to rise with an increase in life expectancy, the proportion of older women will also necessarily rise. It is expected that the number of cases of cancer cervix will rise further in the years to come. Screening programs for cervical cancer have been instituted in developed countries for decades and over a period of time have been shown to be effective in reducing the overall mortality from this disease. Such programs however can only be made to work provided the necessary infrastructure and funds are available (5).Visual inspection of the cervix both unmagnified 
and magnified has been shown to be effective in reducing the morbidity associated with cervical cancer. For optimal strategies of cervical cancer screening, based upon the concepts that the majority of preinvasive and invasive cervical lesions are visible by 'naked-eye' observation, investigators have developed novel affordable diagnostic tools suitable for large-scale screening of cervical abnormalities.(6) Visual Inspection with Acetic Acid (VIA) and Visual Inspection with Lugol's Iodine (VILI) are two modifications of a direct visual assessment of the cervix, different only in regard to the solutions applied on the cervix. The technique is very simple and consists of an examination of the cervix after acetic acid application. After obtaining the clinical history and performing a general examination, the cervix is exposed using a bivalve speculum. A 3\% dilute solution of acetic acid is then applied to the cervix and any excess liquid is aspirated from the posterior vaginal fornix. The cervix is inspected after one minute. The cervix was illuminated with a $100 \mathrm{~W}$ bright lamp and visually examined ('naked eye' examination). Impression was read according to the Atlas of Visual Inspection, (7) which has many diagnostic possibilities. Visual inspection with Lugol's iodine (VILI) following the completion of VIA, the cervix was stained with Lugol's iodine and the visual impressions were classified into three categories: normal cervix, ectopic cervix, and cervix with suspected cancer. (8).Lugol's iodine stains glycogen-rich vaginal epithelium cells. Proliferative lesions, like CIN or cancer, are composed of cells that contain less glycogen than does the surrounding epithelium. These lesions appear as non-staining areas when Lugol is applied to the cervix, and VILI is therefore classified as 'abnormal cervix'. If ulcerated, friable lesions are found, VILI has been classified as 'suggestive of cancer'. The main purpose of VILI was not to ascertain the diagnosis, but to distinguish between a normal and an abnormal cervix. Lesions which stain acetowhite are regarded as positive for VIA. Those with dull white plaques and faint borders are considered low grade VIA while those with sharp borders are considered high grade VIA. The test is regarded as being negative if no acetowhite lesions are detected. Negative indicates homogeneous staining of the cervix was obtained after application of Lugol's iodine. Positive indicates a well-delimited non-staining area was present. Garbhashaya Grivagata Vrana (cervical ectopy) is characterized with the symptoms of white discharge vaginally, low backache, pelvic discomfort, mucosangveneous discharge, post coital bleeding, irregular menstruation and infertility in childbearing age.

Cervical ectopy is the common benign lesion of cervix. In cervical ectopy (formerly called cervical erosion), the layer of delicate cells that line the cervical canal or uterus(Columnar epithelium) extend on to the outer surface of the cervix, which is usually covered with stronger tissue(Squamous epithelium). Because, the cervix is covered with delicate tissue, it is more easily damaged than normal and has a tendency to bleed.
Other significant pre-malignant lesions of cervix are CIN1, 2, 3. CIN - The term cervical intraepithelial neoplasia was introduced to emphasize the unity of dysplasia and carcinoma in situ. CIN refers to preinvasive dysplasia of cervical epithelial cell or precursor of malignant disease. It is categorized according to the depth of involvement of atypical cells. In India, incidence of CIN is very high; a large number of patients are missed for diagnosis because of lack of screening facilities and lack of awareness in the women. Most of the symptoms and local signs of cervix on per speculum examination are common in many benign and premalignant lesions. Before treating the benign cervical lesions like cervical ectopy, evaluation by screening methods like PAP, VIA and VILI are essential to rule out premalignant lesions. Most CIN lesions spontaneously regress. Left untreated about $70 \%$ of CIN 1 will regress. Many Ayurvedic texts deal with Yonigata vrana chikitsa, Tankan JalaYonidhavan is one yoga from Ras-tarangini. Garbhashaya grivagata vrana i.e. cervical erosion is considered as Yonivrana. This yoga can be done with less cost and does not require any special equipment. The line of treatment is based on Ayurvedic principle considering Dosha-Dushyadushti along with treatment of Vrana.

It has mentioned that Vrana should be managed by Vranashodhan and Vranaropanvidhi.(9)

\section{Aim}

To screen initially all the symptomatic patients with VIA and VILI, followed by treating ectopy with tankan jala yonidhaavana and Aswattha churna orally.

\section{Objective}

- To Study the etiopathogenesis of Garbhashay grivagata vrana (Pittajvrana- kaphanubandhi) W.S.R. to Cervical ectopy.

- To screen all the registered patients with visual inspection by VIA, VILI.

\section{Materials and Methods \\ Study Design}

- The study is open single group prospective study. 112 patients fulfilling the inclusion criteria were selected from the OPD of Prasutitantra and Striroga, between the age group of 20 years to 60 .

- The selected patients were subjected to a careful clinical examination the data acquired from them were recorded in the research proforma.

- After general examination, gynaecological examination was carried out. Inspection, palpation, per speculum examination and pervaginal examination were done to note degree, size, and appearance of cervical ectopy.

- Routine investigation of blood and Urine i.e. Complete blood count, and Urine routine and microscopic were done. All cases were ruled out for HIV.Clinically acute cervicitis with muco purulent discharge vaginally,systemic involvement with fever, severe tender fornices and raised white cell count were not considered 
for the study which need to be treated with systemic antibiotics and STD need to be ruled out which is difficult in the centre where the study is conducted. More than $70 \%$ of patients underwent repeated course of systemic antibiotics.

- Cases with Aceto white positive lesions and negative uptake of iodine were referred to higher centre for colposcopy and biopsies to rule out pre-malignant and invasive carcinoma cervix.

\section{Visual inspection with Acetic acid 3 \%( VIA) Procedure}

It involves naked eye inspection under bright light after 1 minute after application of 3\% acetic acid using a cotton swab.

The observer should specifically look for acetowhite areas in the TZ (Transformation zone).

\section{VIA Positive}

- Distinct, well defined dense (opaque, dull, oester white) acetowhite areas with regular or irregular margins, close to abutting SCJ (Squamo-columnar junction) in the $\mathrm{TZ}$ or close to the external os.

- Strikingly dense acetowhite areas in the columnar epithelium.

- Entire cervix becomes densely white.

- Condyloma and leukoplakia occur close to the SCJ, turns intensely white.

\section{VIA Negative}

- No aceto white lesions observed on cervix.

\section{Visual inspection with lugol's iodine (VILI) \\ Procedure-}

Liberally and gently Lugol's iodine is applied with a cotton swab on cervix, after removing swab carefully examination is done for any iodine non-uptake (non-staining) areas in the form of pale or yellowishwhite areas, particularly in the TZ close to the SCJ.

\section{VILI Positive}

- Thick, bright, mustard-yellow or saffron-yellow iodine non-uptake areas are seen in the TZ, close to or abutting the SCJ, or when entire cervix turns densely yellow.

\section{VILI Negative}

- The squamous epithelium of cervix turns mahogany brown or black and the columnar epithelium does not change colour.

\section{Advantages}

- Procedure is simple, inexpensive.

- It can be done in OPD setup.

- Results available immediately.

- Does not require sophisticated equipment.

\section{Inclusion Criteria}

- Age group from 20 years to 60 years(married)

- Cervical Ectopy (Erosion)

- Patients with symptoms of persistent leucorrhea, Pelvic pain, Contact bleeding, Backache.
Exclusion Criteria

- CIN1, 2,3(Cervical Intraepithelial Neoplasia )

- Invasive carcinoma

- Carcinoma in situ.

- Cervicitis (Acute and chronic)

- HSIL (High Grade Squamous Intraepithelial Lesions)

- Oral contraceptive pill users

- Post natal cases

- Post H/O Radio and chemotherapy

- Warts

\section{Discontinuation Criteria}

- Any local irritation,

- Patient not willing for continuation of treatment,

- Not coming for regular follow up.

\section{Clinical Intervention \\ Oral Treatment}

- Drug - Ashwattha twak churna

- Dose -6 gms in two divided doses per day

- Time - Morning and Evening

- Anupana-Koshna Jala

- Duration of treatment - 2 months

\section{Local Treatment}

- Drug-Tankan Jala for external use.

- Amount-100ml.

- Route - Deep Intravaginal

- Time-Morning

- Duration of Yonidhavan(Douching) - Till the Tankana Jala completes, Duration of treatment daily for 14 days .

- For 2 cycles, post menstrual, after the cessation of menstrual flow completely.

\section{Criteria for Assessment}

Subjective Criteria

Leucorrhoea

- Grade 0:No discharge

- Grade 1:Mucoid discharge mild staining on under garments

- Grade 2:Mucoid discharge excessive staining

- Grade 3:Needs pads

\section{Contact bleeding}

- Grade 0:No contact bleeding

- Grade 1:Contact bleeding on defecation

- Grade 2:Contact bleeding after sexual intercourse

- Grade 3:Blood stain white discharge

Backache

- Grade $0=$ Backache Absent,

- Grade 1 = Backache Present.

\section{Pelvic discomfort}

- Grade 0 :No pelvic discomfort

- Grade 1:Dull ache in abdomen does not disturb routine work

- Grade 2:Dull ache, disturbs routine work

- Grade 3:Needs medication 
Objective Criteria

Bright red area of Portiovaginalis of cervix

- Grade 0 : No bright area

- Grade 1:Extending more than $1 \mathrm{~cm}$ from os

- Grade 2:Extending 1-2cm from os

- Grade 3: Extending $>2 \mathrm{~cm}$ Area measured with the help of tissue holding forceps over measuring scale.

VIA-Acetowhite changes

- Grade $0=$ Absent

- Grade 1 = Present

VILI-Lugol's iodine colour non uptake

- Grade $0=$ Absent

- Grade 1 = Present

GRADATION IS GIVEN AS ZERO FOR GOOD RESPONSE / PATHOLOGY ABSENT, GRADES 2 AND 3 ARE GIVEN FOR NO RESPONSE / PATHOLOGY PRESENT.

\section{Observations}

\section{Demographic distribution}

Out of 100 patients, 56 patients $(56 \%)$ were with age $20-30$ years and 5 patients $(5 \%)$ were with age 50 - 60 years. 33 patients $(33 \%)$ were from poor class while 67 patients $(67 \%)$ were from middle class. In 21 patients $(21 \%)$ there were menstrual irregularities while in 79 patients $(79 \%)$ it was absent. Leucorrhoea, Backache, Pelvic discomfort and redness were observed in all 100 patients included in the study. Contact bleeding was present in 4 cases which were positive for VIA and VILI.

\section{Graph.no.1}

Incidence of Socio-Economic status

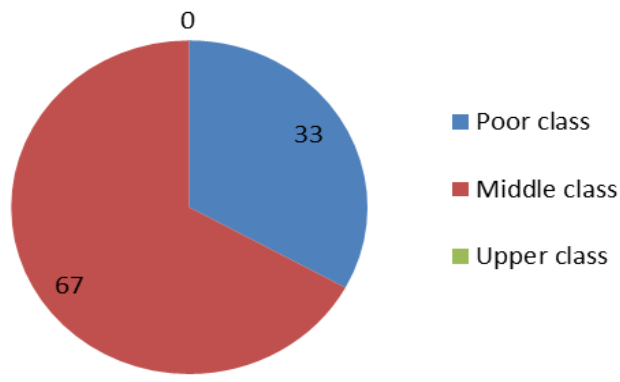

Table no.1: Incidence of Menstrual irregularities

\begin{tabular}{|c|c|c|c|}
\hline \multirow{2}{*}{ Sr. No. } & M.C. & \multicolumn{2}{|c|}{ No. of patients } \\
\cline { 3 - 4 } & Irregularities & Count & \% \\
\hline 1 & Absent & 79 & $79.00 \%$ \\
\hline 2 & Present & 21 & $21.00 \%$ \\
\hline
\end{tabular}

Table.no.2 Statistical Analysis of the Assessment criteria.

\begin{tabular}{|c|c|c|c|c|c|c|c|c|c|}
\hline \multirow{3}{*}{$\begin{array}{l}\text { Signs and } \\
\text { symptoms }\end{array}$} & \multirow{3}{*}{$\mathrm{n}$} & & \multicolumn{5}{|c|}{ Score } & \multirow{3}{*}{$\begin{array}{c}\text { Friedman } \\
\text { Chi-Square } \\
\text { test }\end{array}$} & \multirow{3}{*}{ P - Value } \\
\hline & & & \multirow{2}{*}{ B.T. } & \multicolumn{4}{|c|}{ A. $T$. } & & \\
\hline & & & & $1^{\text {st }} M$ & $2^{\text {nd }} M$ & $6^{\text {th }} M$ & df & & \\
\hline \multirow{2}{*}{ Leucorrhoea } & 100 & Median & 3 & 2 & 1 & 1 & 3 & 231.21 & $<0.001$ \\
\hline & 100 & Mean & 2.58 & 1.93 & 1.27 & 0.69 & & & \\
\hline \multirow{2}{*}{ Backache } & $\overline{100}$ & Median & 1 & 1 & 1 & 0 & 3 & 130.09 & $<0.001$ \\
\hline & 100 & Mean & 1.05 & 0.91 & 0.54 & 0.37 & & & \\
\hline \multirow{2}{*}{$\begin{array}{l}\text { Pelvic } \\
\text { discomfort }\end{array}$} & 100 & Median & 2 & 2 & 1 & 0 & 3 & 239.87 & $<0.001$ \\
\hline & $\overline{100}$ & Mean & 2.36 & 1.61 & 1.04 & 0.43 & & & \\
\hline \multirow{2}{*}{ Redness } & 10 & Median & 2 & 2 & 1 & 0 & 3 & 233.15 & $<0.001$ \\
\hline & 10 & Mean & 2.39 & 1.64 & 1.02 & 0.56 & & & \\
\hline
\end{tabular}

B.T-Before treatment, A.T-After treatment,

$1^{\text {st }} \mathrm{M}$ - First Month, $2^{\text {nd }} M-$ Second Month, $6^{\text {th }} M-$ Sixth month, df - Degree of freedom, $n$ - Number of patients 
Graph. 2

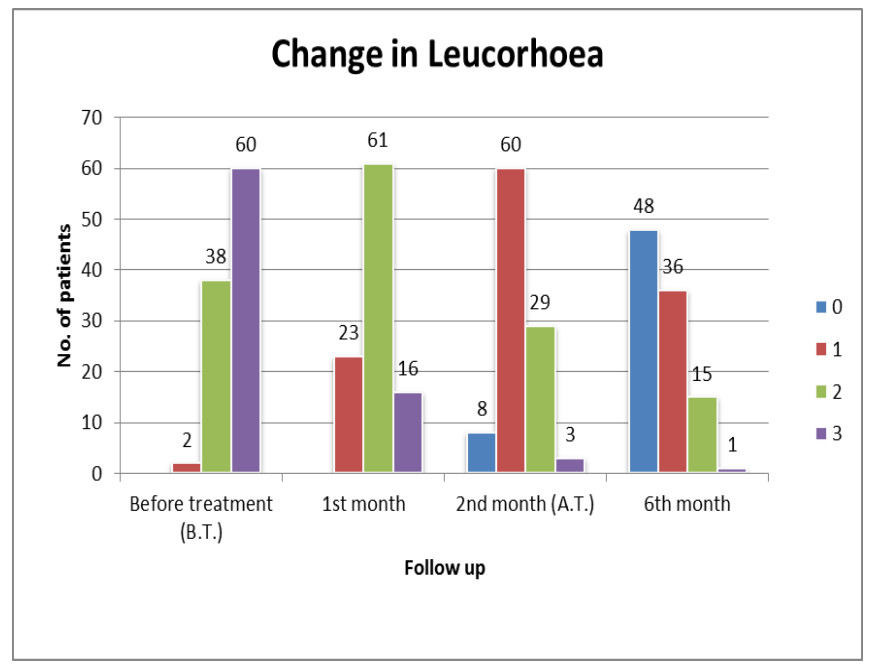

Graph. 4

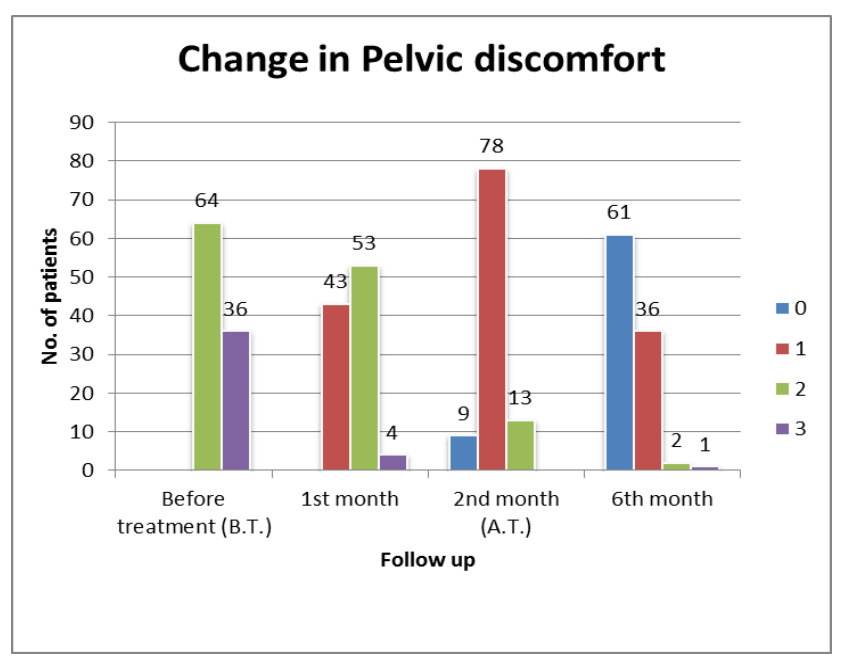

Graph. 3

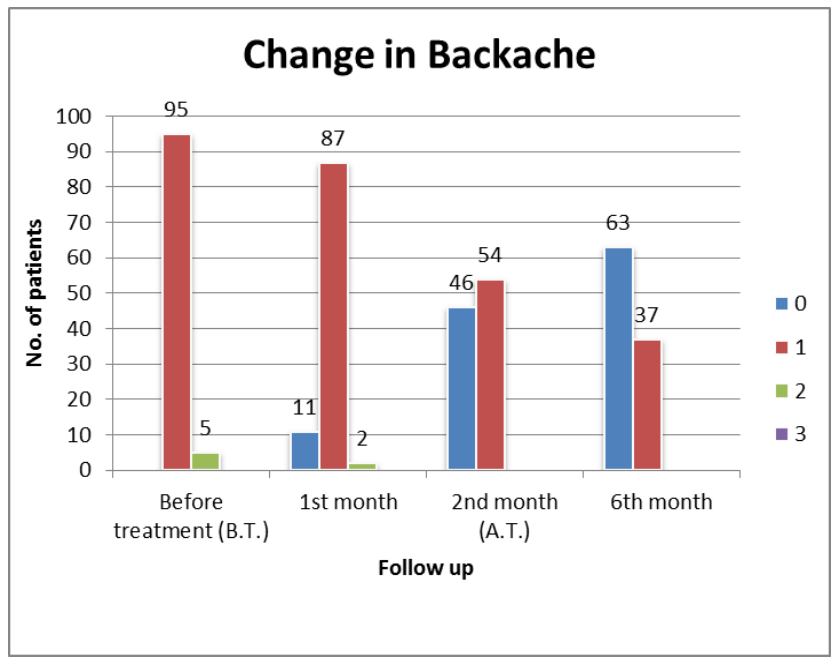

Graph. 5

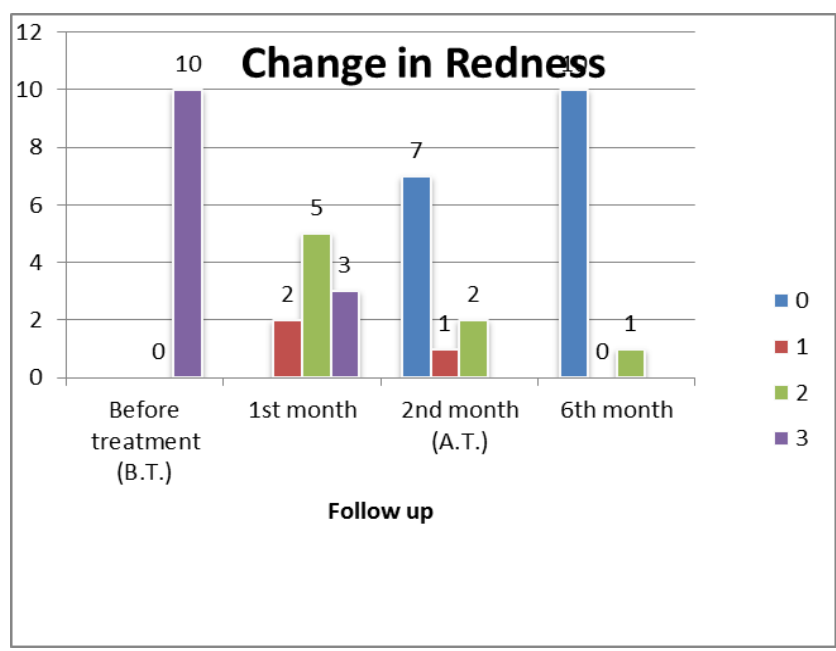

Graph. 6

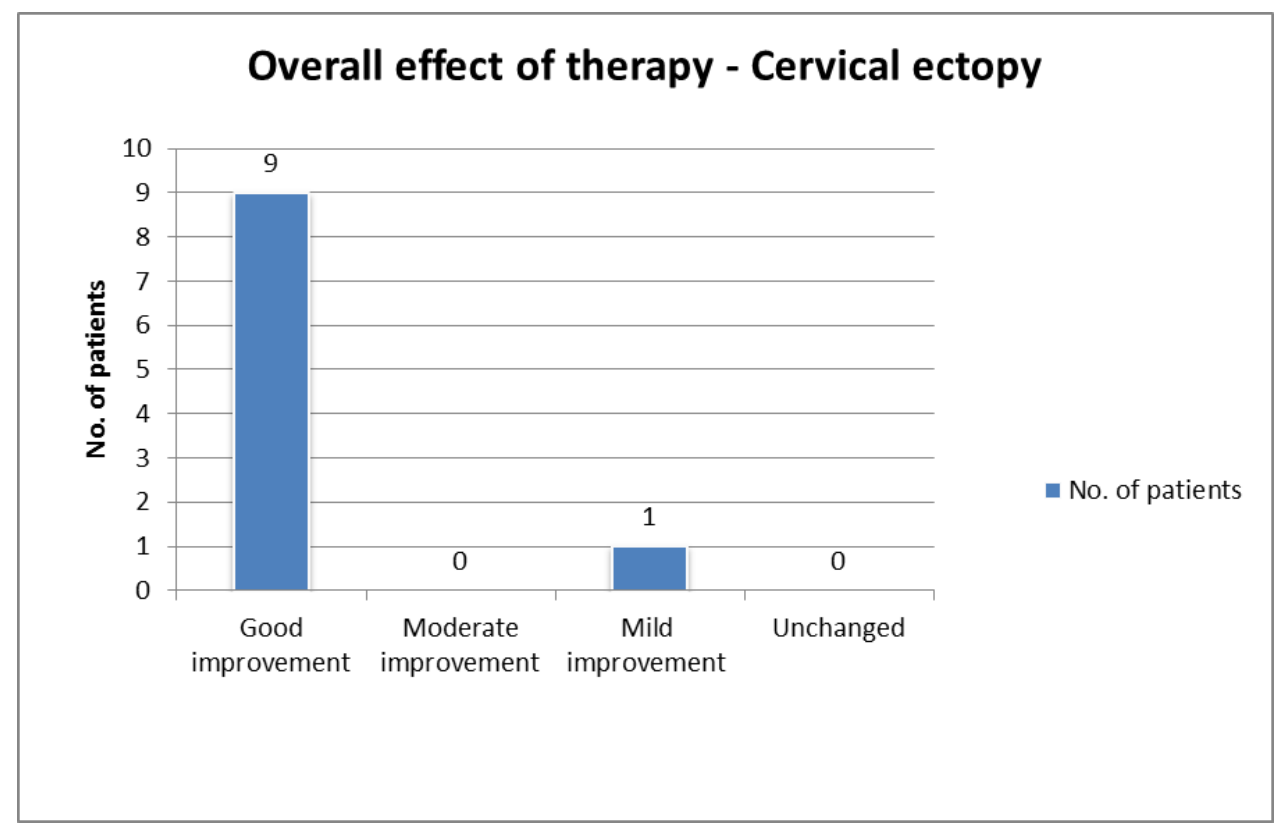




\section{Discussion}

Screening the symptomatic patients of leucorrhea, pelvic discomfort, backache, contact bleeding with VIA and VILI proved effective in identifying the premalignant lesions and invasive carcinoma. Out of 7 suspected patients [table] on visual inspection 4 were confirmed with Cervical Intraepithelial neoplasia (CIN1) on biopsy and 1with Invasive carcinoma. 2 patients did not follow up. Visual inspection with Acetic Acid (VIA) showed higher sensitivity compared to Pap smear. In a comparative study between Pap smear and visual inspection with acetic acid (VIA) in screening of CIN and early cervical cancer VIA has low specificity as compared to Pap smear. It was observed that there is a significant association between the histopathology report and the Pap smear report as far as the negative predictive value is concerned. Accuracy of VIA is $87 \%$ compared to $93 \%$ in Pap smear. Negative predictive value of VIA is $99 \%$ as compared to $96 \%$ in Pap smear. Positive predictive value is $45 \%$ in Pap smear as compared to $32 \%$ in VIA. (10).

Cervical ectopy is a very common disease in woman but there is no any direct reference or explanation about it in Ayurvedic classics. Many research workers have tried to attribute cervical ectopy with one or other type of yoni-roga. All the workers included ectopy under yoni-roga. Some correlated it with karniniyonivyapad. According to Ayurvedic moulika siddhanta(Basic principles of Ayurveda). Vitiation of any dosha will cause vyadhi. Here Pittaja and KaphajaVrana signs and symptoms are correlated as cervical ectopy because the description and characteristic features of the disease are co-insiding with description of cervical ectopy .

\section{Mode of action of drug:}

As the Garbhashay Grivagata vrana has Pittakapha dominance in the pathogenesis, it requires treatment which has property of pitta-kaphahara.

\section{Action of Tankan :}

When the kshara applied on the mucous membrane, first there will be irritation followed by inflammatory process resulting in to oedema, dragging pain, and pressure pain causing separation of dushtavrana and clearing all signs and symptoms of disease. The presence of proteolytic enzymes is capable for its corrosive, caustic, anti-microbial and bactericidal properties. Tankan is katu in rasa so it works as Kaphashamak and vrana-avasadak. It absorbs kapha and promotes healing of cervical ectopy. It acts as vividhavrananashan by its properties like katu rasa, ushnavirya,rukshaguna.(11)

Tankan is borax, and it is alkali in nature. It has anti-inflammatory and healing properties. It is antiseptic, anti-bacterial, antifungal and astringent in nature.

Ashwattha is kashaya in rasa and having properties like ruksha, shita,sangrahi. It eliminates kleda (discharge), dushtasrava. Therefore it helps in healing of cervical erosion. (12)

Substance which join together broken asthis, torn dhatus, and heal injured blood vessels known as sandhaniya. Vrana is charecterized by destruction or tear of the normal epithelial tissue. Ashwattha due to ruksha, shitaguna alleviates the kapha and pitta, absorbs kleda, oozing from dhatus and heal torn blood vessels by its kasaya rasa. Therefore helps in healing of cervical ectopy.(13)

\section{Conclusion}

The aim to screen initially all the symptomatic patients with VIA and VILI, followed by treating ectopy with tankan jala yonidhaavana and Aswattha churna orally proved beneficial in all the patients.

By Regular screening cell changes can be detected in the cervix at the earliest .Screening of all patients is effective in diagnosis of premalignant and malignant lesions to reduce the risk of cervical cancer.

Out of 100 patients 10 patients were having cervical ectopy and 4 patients were CIN-1 positive and 1 with invasive carcinoma.

Screening with VIA (Visual Inspection with Acetic acid) and VILI (Visual Inspection with Lugol's Iodine) help to avoid error in diagnosing benign, pre-malignant and malignant lesions.

Role of Tankan Jala Yonidhavan has good result on the objective criteria of assessment like redness of portio vaginalis, which shows Vranashodhan, Vranaropan activity, and on the subjective criteria like leucorrhoea, backache, pelvic discomfort.

\section{References}

1. Parikh DM, Pisani P, Ferlay J et al. Estimates of the world wide Incidence of cervical cancer.

2. Int J Cancer 1993;54:594-606. WHO/ICO information centre on HPV and cervical cancer (HPV information centre). Summary report on HPV and cervical cancer statistics in India 2007.

3. Bishop A, Sherris TJ. Cervical dysplasia treatment: key issues for Developing countries. Bull Pan Am Health Organ 1996; 30:378-86.

4. Solomon D, Davey D, Kurman R et al. The 2001 Bethesda system: Review article 122

5. Terminology for reporting of cervical cytology. JAMA 2002; 28

6. Sauvaget C, Fayette JM, Muwonge R, Wesley R, Sankaranarayanan R. Accuracy of visual inspection with acetic acid for cervical cancer screening. Int J Gynaecol Obstet. 2011; 113:1424.

7. Sankaranarayanan AR, MD, France Ramani S. Wesley, MD Regional Cancer Centre, Thiruvananthapuram, India, International Agency for Research on Cancer Lyon, Practical Manual on Visual Screening for Cervical Neoplasia

8. Sankaranarayanan R., Shyamalakumary B., Wesley R., Sreedevi Amma N., Parkin D.M., Krishnan Nair M.(1999) Visual inspection with acetic acid in the early detection of cervical cancer 
ISSN: 0976-5921

Vishala Srinivas T et.al., Visual Inspection of Cervix with VIA \& VILI in the management of Cervical Ectopy and recursors. Int. J. Cancer, 80,161-163.

9. Yadavji Trikamji,. Sushruta Sutra Sthan 27/7; Sushruta Samhita, Nibandha sangraha; p. 108, Reprint ed. Varanasi: Chaukhambha orientalia; 2009

10.Bhattacharyya AK, Nath JD, Deka H. J Midlife Health. 2015 Apr-Jun; 6(2):53-8. doi: 10.4103/0976-7800.158942.

11.Yadavji Trikamji, (Sushrutha samhita chikitsa sthana.1/74)
12.Chunekar KC, Bhavprakash Nighantu, Addhyaya Vatadivarga,Page no.363, Chukhamba Bharati Academy, Varanasi. Reprint 2009.

13.Acharya Priyavat Sharma,Dhanvantari Nighantu, Chaukhamba Orientalia, Varanasi, 2nd Ed.

14. Rama Chandra Reddy, Bhaishajya Kalpana Vidnyanam, Chaukhamba Sanskrut Bhavan Varanasi, 2nd Ed,Reprint 2001.

Figure 1: Showing the pictures of Ectopy of Cervical Os in plain view, after applying VIA and VILI, before and after the treatment in various patients

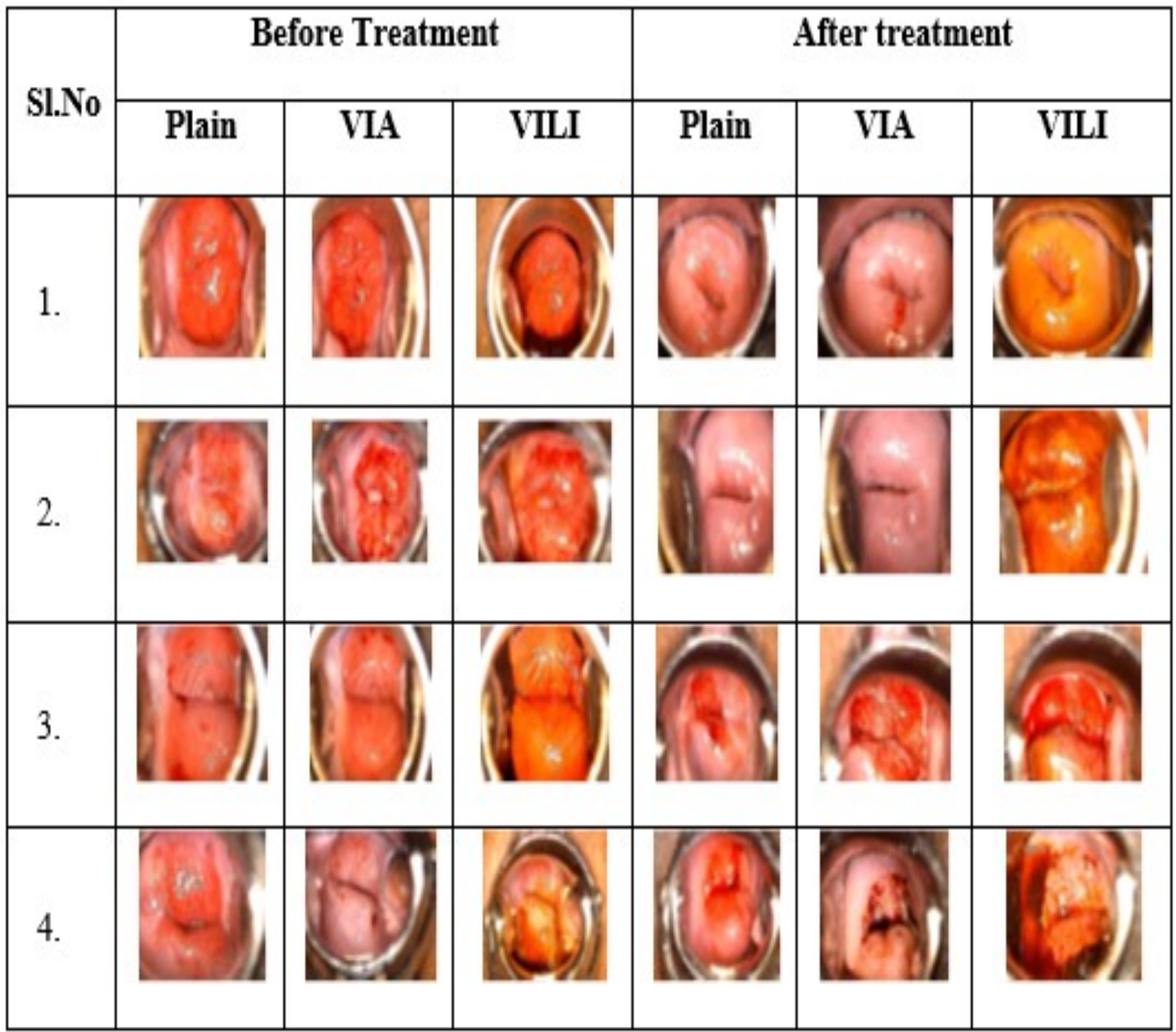


Figure 2: Showing the abnormal cervix in plain view, after applying VIA and VILI in various patients

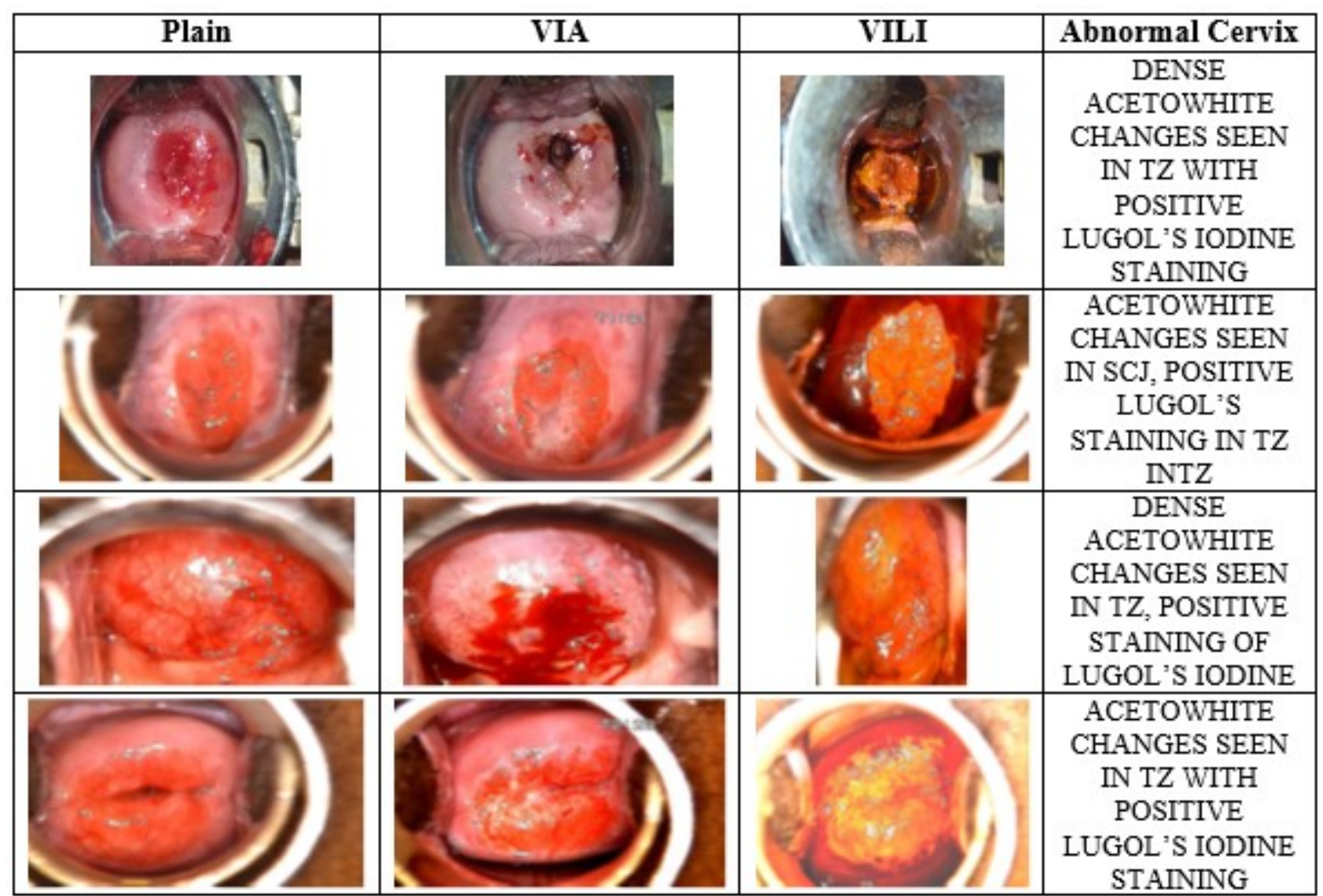

